\title{
8
}
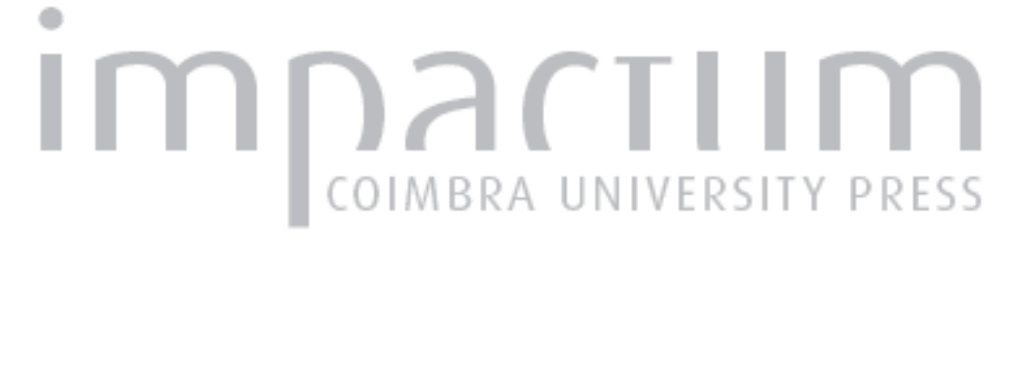

\section{Gestão pública e riscos ambientais relacionados a processos erosivos: caso de São Pedro, São Paulo, Brasil} \author{
Autor(es): $\quad \begin{array}{ll}\text { Perez-Filho, Archimedes; Carpi Junior, Salvador; Quaresma, Cristiano } \\ \text { Capellani }\end{array}$
}

Publicado por: Associação Portuguesa de Riscos, Prevenção e Segurança

URL

persistente:

URI:http://hdl.handle.net/10316.2/36075

DOI:

DOI:http://dx.doi.org/10.14195/1647-7723_18_19

Accessed : $\quad$ 26-Apr-2023 14:53:28

A navegação consulta e descarregamento dos títulos inseridos nas Bibliotecas Digitais UC Digitalis, UC Pombalina e UC Impactum, pressupõem a aceitação plena e sem reservas dos Termos e Condições de Uso destas Bibliotecas Digitais, disponíveis em https://digitalis.uc.pt/pt-pt/termos.

Conforme exposto nos referidos Termos e Condições de Uso, o descarregamento de títulos de acesso restrito requer uma licença válida de autorização devendo o utilizador aceder ao(s) documento(s) a partir de um endereço de IP da instituição detentora da supramencionada licença.

Ao utilizador é apenas permitido o descarregamento para uso pessoal, pelo que o emprego do(s) título(s) descarregado(s) para outro fim, designadamente comercial, carece de autorização do respetivo autor ou editor da obra.

Na medida em que todas as obras da UC Digitalis se encontram protegidas pelo Código do Direito de Autor e Direitos Conexos e demais legislação aplicável, toda a cópia, parcial ou total, deste documento, nos casos em que é legalmente admitida, deverá conter ou fazer-se acompanhar por este aviso.

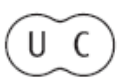




\section{territorium}

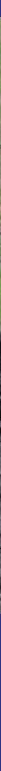

\section{Afirmar as Ciências Cindínicas}

Revista da Associação Portuguesa de Riscos, Prevenção e Segurança 


\section{GESTÃO PÚBLICA E RISCOS AMBIENTAIS RELACIONADOS A PROCESSOS EROSIVOS: CASO DE SÃO PEDRO, SÃO PAULO, BRASIL*}

Archimedes Perez-Filho

Professor Titular - Departamento de Geografia- Instituto de Geociências Universidade Estadual de Campinas (IG-Unicamp). archi@ige.unicamp.br

Salvador Carpi J unior

Doutor - Profissional de Pesquisa - Departamento de Geografia Instituto de Geociências - (IG-Unicamp). salvador@ige.unicamp.br

Cristiano Capellani Quaresma

Doutorando - Programa de Pós-Graduação em Geografia Instituto de Geociências - (IG-Unicamp). cristiano.quaresma@ige.unicamp.br

\section{RESUMO}

O objetivo deste trabalho é demonstrar criticamente a forma pela qual a questão da erosão tem sido tratada no município de São Pedro (Brasil) ao longo das últimas décadas. Os riscos associados aos processos erosivos presentes na área de estudo têm sido agravados por ações inadequadas da Gestão Pública municipal, decorrentes principalmente do distanciamento desta em relação ao meio acadêmico.

Palavras-chave: Erosão acelerada; Poder Público; Uso e Ocupação

\section{RESUMEN}

Administración pública y riesgos ambientales relacionados con los procesos de erosión: el caso de San Pedro, San Pablo, Brasil - El objetivo de este estudio es criticar la forma como ha sido tratada la cuestión de la erosión en la municipalidad de São Pedro (Brasil) en las últimas décadas. Los riesgos asociados a la erosión actual en el área de estudio se han visto agravados por las acciones inadecuadas de la Gestión Pública municipal, principalmente como resultado de su distanciamiento en relación al mundo académico.

Palabras clave: erosión acelerada; Gobierno; Uso y Ocupación.

\section{RESUMÉ}

L'administration publique et risques environnementaux liés aux processus d'érosion: le cas de Saint-Pierre, Sao Paulo, Brésil - L'objectif de cette étude est de démontrer à quel point la question de l'érosion a été traitée dans la municipalité de São Pedro (Brésil) au cours des dernières décennies. Les risques associés à l'érosion actuelle dans la zone d'étude ont été aggravées par l'insuffisance des actions de la municipalité dans la gestion publique, principalement en raison de son éloignement du milieu universitaire.

Mots-clés: érosion accélérée; gouvernement; Utilisation et occupation.

\section{ABSTRACT}

Public administration and environmental risks related to erosion processes: the case of São Pedro, Sao Paulo, Brazil The aim of this work is to show critically the way that erosion has been treated in São Pedro town (Brazil) all over the last decades. The risks associated to the erosion in the studied area have been aggravated by inadequate actions by de Public Management. This can be explained manly by its distance in relation to the academic agreement.

Key-words: Erosion; Public Management; Use and Occupation.

* O texto deste artigo corresponde à comunicação apresentada ao II Congresso Internacional de Riscos e VI Encontro Nacional, tendo sido submetido para revisão em 29-05-2010, tendo sido aceite para publicação em 18-07-2010.

Este artigo é parte integrante da Revista Territorium, n. 18, 2011, RIscos, ISBN: 0872- 8941. 


\section{Introdução}

Os processos erosivos na Estância Turística de São Pedro tem sido abordados por inúmeros pesquisadores de importantes universidades brasileiras. As motivações que levaram a realização de tais estudos referem-se, entre outros, a proximidade de universidades localizadas na região, o acesso relativamente fácil à área, e a presença de diversos aspectos de interesse da Geografia, Geologia, Geomorfologia, Pedologia e Gestão Ambiental, como por exemplo, os processos erosivos de grande intensidade.

No entanto, apesar dessa grande produção técnica e acadêmica sobre essa área de estudo, a erosão e os riscos ambientais presentes na mesma não são resolvidos de forma satisfatória.

Nesse sentido, o objetivo deste trabalho é demonstrar criticamente a forma pela qual a questão da erosão tem sido tratada em São Pedro nas últimas décadas, agravando ou criando novas situações de risco.

O município de São Pedro está situado na região sudeste do Brasil, no setor centro-leste do Estado de São Paulo (fig. 1) entre as coordenadas aproximadas de $22^{\circ} 41^{\prime} \mathrm{e}$ $22^{\circ} 26^{\prime}$ de latitude sul e 48ㅇ $05^{\prime}$ e 470 47' de longitude oeste.

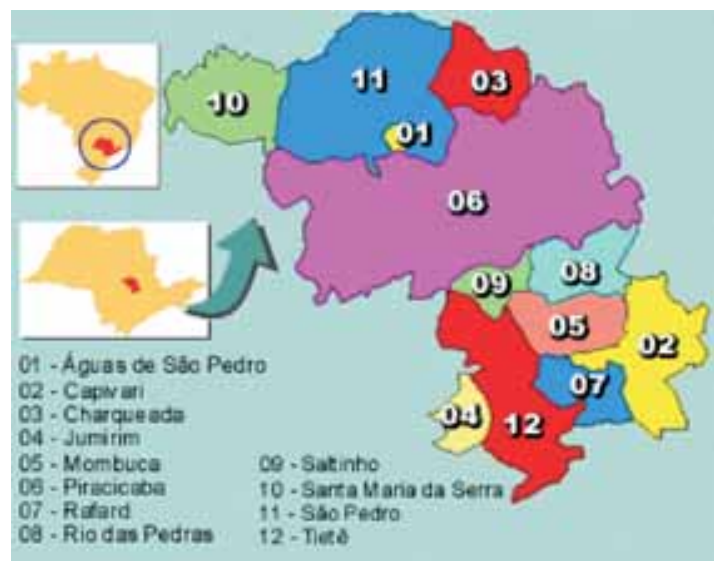

Fig. 1- localização da Estância Turística de São Pedro (s/ esc.). Fonte: http:// www. citybrazil.com. br/sp/regioes/piracicaba/

Em termos geomorfológicos, o município situa-se na faixa de transição entre a Depressão Periférica Paulista e as Cuestas Arenito-Basálticas, sendo que sua área urbana encontra-se localizada na primeira unidade citada, caracterizada por relevos suaves e de baixa amplitude altimétrica.

A rede hidrográfica do município está representada pelo Rio Piracicaba e seus afluentes, com destaque para o Ribeirão Araquá, e abrigando muitas nascentes, formando os principais rios e ribeirões da região. A área do topo e reverso da cuesta de São Pedro corresponde à zona de recarga do Aquífero Guarani, enquanto que a descarga do aqüífero encontra-se no sopé da serra, onde fica a maior parte da área municipal.

\section{Fatores condicionantes da dinâmica erosiva}

Os estudos realizados por pesquisadores de diversas áreas do conhecimento acadêmico têm procurado entender e explicar a gênese e localização preferencial dos processos erosivos intensos presentes na área.

Tais trabalhos podem ser divididos em pelo menos dois grupos: aqueles que atribuem a aceleração dos processos erosivos a fatores naturais, considerando a susceptibilidade erosiva inerente aos aspectos do meio físico; e outro grupo que atribui tais processos à ação antrópica.

Embora existam divergências entre os pesquisadores ao estudarem os aspectos geológicos da área, todos apontam as características litológicas aí presentes como favoráveis à instalação de processos erosivos, destacando os depósitos coluviais arenosos, de fraco grau de consolidação (friáveis), os quais apresentam baixa resistência à erosão pelo escoamento sub e superficial da água. Estes depósitos sedimentares existentes na área tem idade atribuída ao Quaternário, e correspondem à Formação Rio Claro, constituída de sedimentos arenosos recentes, datados do Neocenozóico.

Tais depósitos recobrem deposições mais antigas relativas às Formações Pirambóia, do Triássico, e Botucatu, do Jurássico-cretáceo. A primeira caracteriza-se por uma sequência de camadas arenosas geralmente vermelhas, de granulação média a fina, ocorrendo, localmente, arenitos grossos e conglomeráticos, ou então, lâminas de silte ou argila, e apresentando estratificação dos tipos plano-paralela e cruzada. Quanto a Formação Botucatu, constitui-se quase totalmente de arenitos de granulação fina a média, uniforme e com boa seleção de grãos foscos de alta esfericidade, avermelhados, e apresentam estratificação cruzada de médio a grande porte (IPT, 1981). As condições climáticas vigentes na época de deposição desses sedimentos, caracterizavam-se por uma crescente aridez, passando-se da deposição predominantemente fluvial em canais meandrantes e planícies de inundação, típicas da Formação Pirambóia, para um ambiente progressivamente desértico, com o empilhamento de grandes dunas caminhantes, característico da Formação Botucatu.

A estes fatores podem ser somados a ocorrência de lineamentos estruturais, constituídos por falhas, juntas e acamamento local izados em várias porções da bacia. Estas descontinuidades estruturais, segundo FACINCANI (1995), ao serem reativadas por eventos tectônicos, permitiriam a alteração de litotipos por intermédio da percolação de águas, e conseqüentemente a gênese de formas lineares de erosão. Cabe lembrar aqui, a concentração de aqüíferos em zonas de baixos estruturais, em virtude da presença de desníveis altimétricos em comparação a áreas vizinhas, juntamente com o terreno fraturado. Assim, as 
condições geológicas próprias da área influenciam não somente nas características do escoamento superficial da água, mas inclusive aquelas referentes ao fluxo subterrâneo na dependência de gradientes hidráulicos. Todos estes fatores contribuem ao surgimento de formas de erosão linear acelerada - voçorocas.

Os fatores pedológicos também concorrem na predisposição deste setor aos processos erosivos, dado o predomínio de solos de textura arenosa, às vezes média, sendo profundos e bem drenados nos interflúvios tabuliformes e habitualmente argissolos naqueles mais dissecados

Destacam-se os argissolos vermelho-amarelos, com problemas de susceptibilidade à erosão, que aumenta com a declividade. Quanto à textura, predominam aqueles de textura entre média e arenosa, enquanto que os problemas de fertilidade mais graves estão naqueles do tipo álicos e nos distróficos (Oliveira, J AComine e Camargo, 1992).

Os Neossolos Quartzarênicos ocorrem principalmente na porção ocidental e setentrional da área, capeando os tôpos dos interflúvios que avançam em direção ao interior da bacia. Tratam-se de solos profundos, essencialmente quartzosos, com textura arenosa ou franco arenosa ao longo de pelo menos $2 \mathrm{~m}$ de profundidade.

Perez Filho et al. (1986) ressaltam que características dos Neossolos Quartzarênicos (Areias Quartzosas) tais como granulometria e taxa de infiltração média, aliadas às condições topográficas e do uso rural e urbano das terras da região de São Pedro, tornam tais solos altamente susceptíveis de serem atacados por processos erosivos normais e acelerados. Tais autores realizaram análise das modificações dos processos erosivos em função das variações pluviométricas, medidas em campo, e do uso da terra, que chegaram a apontar, no período de 30 dias, a instalação de voçorocas de até $28 \mathrm{~m}$ de comprimento por $4 \mathrm{~m}$ de profundidade. 0 uso dos Neossolos Quartzarênicos como suporte ao reflorestamento de eucaliptos também apresenta, segundo os autores, problemas erosivos, mesmo em declividades relativamente reduzidas da ordem de 8 a $10 \%$

A análise integrada dos diferentes elementos componentes da Bacia do Ribeirão Araquá, realizada por CARPI J R (1996) tomando-se por base as unidades geomorfológicas identificadas, permitiu estabelecer as unidades Pedimentos Tabuliformes e Pedimentos Dissecados, como as áreas mais susceptíveis à ação de processos erosivos, principalmente em relação à erosão linear acelerada. Neste caso, os atributos morfométricos desempenham um papel fundamental em permitir a ação erosiva, associando-se as características morfopedológicas locais. Ambas as unidades geomorfológicas em questão mostram geralmente, valores elevados de energia do relevo (declividade e índices de dissecação), notadamente nos setores mais dissecados.

A energia do relevo forte ou muito forte presente nesses setores traz implicações importantes nas características do escoamento pluvial e fluvial, e conseqüentemente na ação dos processos erosivos. Assim, no escoamento pluvial, a capacidade erosiva da água da chuva, ao descer através das vertentes, é maior sob tais condições devido à maior velocidade e quantidade atingidas pela fluxo de água. No escoamento fluvial, por sua vez, a energia do relevo mais intensa propicia a atuação erosiva dos cursos d'água, contribuindo para o seu alargamento, aprofundamento do leito e erosão remontante. Assim, a dinâmica pluvial e fluvial atuando de forma conj unta sob tais condições de morfometria do relevo, vem facilitar de maneira significativa ao aparecimento e evolução das formas de erosão nesses setores da bacia.

Entretanto, deve se considerar ainda a variabilidade sazonal e anual das chuvas que precipitam sobre a região. Em termos de quantidade anual de chuva, a bacia pode ser considerada como receptora de elevadas precipitações pluviométricas, em torno de 1300 a 1400 $\mathrm{mm} / \mathrm{ano}$, acentuadas ainda mais pelo efeito orográfico referente às Serras de São Pedro e Itaqueri, Iocalizadas nas proximidades. As chuvas decorrentes desse efeito fazem-se sentir, não somente nessas altitudes mais elevadas, mas inclusive nos setores mais próximos da voçoroca.

A concentração de chuvas - $80 \%$ entre outubro e março - de primavera e verão, por sua vez, colabora com o aumento da agressividade ou intensidade das precipitações, isto é, de sua capacidade erosiva. Merecem atenção também as variações anuais pluviométricas, que permitem a intensificação de processos erosivos em anos mais chuvosos.

Diante deste quadro, fica evidenciado que os terrenos mais propensos à ação erosiva encontram-se em estado de equilíbrio extremamente precário. Este equilíbrio é facilmente superado sob influências externas, representadas pela ação das chuvas e do homem, considerando-se ainda a possível interferência de eventos neotectônicos.

Embora a capacidade erosiva da chuva tenha condições de interferir substancialmente no desenvolvimento dos processos erosivos da área, a ação antrópica é atualmente a mais importante. O homem, através do uso agrícola e urbano do solo, impõe modificações que permitem com que os limites críticos de resistência das formas de relevo em relação aos processos erosivos sejam mais facilmente atingidos.

A ocupação agrícola das terras, processada desde 0 século XIX, provocou a destruição de grande parte da cobertura vegetal original, correspondente às matas, 
cerrados e campos naturais, que constituía em um fator importante de proteção do solo á erosão. A retirada das matas favorece a ação do impacto da gota de chuva sobre o solo (efeito splash) e promove um incremento do escoamento superficial da água em detrimento da infiltração.

Somando-se às conseqüências trazidas pela exploração agrícola das terras, deve-se mencionar também os problemas causados pelas obras civis, com destaque à rede viária local e a instalação e expansão dos núcleos urbanos. As estradas foram construídas sem respeito as peculiaridades físico-naturais, e expuseram diretamente ao impacto da chuva terrenos altamente friáveis e de baixo poder de resistência aos processos plúvio-erosivos.

As áreas urbanas, à medida que foram se desenvolvendo, passaram a se constituir em superfícies progressivamente menos permeáveis, em comparação a cobertura vegetal primitiva, motivando o aumento da água escoada superficialmente. Assim, as ruas tornam-se freqüentemente vias de concentração de escoamento, sobretudo quando acompanham o sentido da inclinação das vertentes ou dos canais pluviais, contribuindo para o desenvolvimento de sulcos e ravinas.

Outra atividade antrópica que deve ser reportada como fator influenciador na dinâmica erosiva da Bacia do Córrego Tucum consiste na implantação dos chamados portos de areia às margens dos canais fluviais. Os portos de areia são instalações destinadas à extração do material arenoso depositado pelos cursos d'água, oriundo da erosão ocorrida nas áreas à montante. A extração contínua da areia provoca um rebaixamento constante do nível de base dos cursos fluviais que a depositam, dificultando o estabelecimento de um estado de equilíbrio de seus perfis Iongitudinais. A dificuldade na chegada a esse perfil de equilíbrio Iongitudinal reflete-se na manutenção da capacidade erosiva do curso fluvial, impedindo a estabilização dos processos erosivos posicionados à montante.

Desse modo, constata-se que a localização predominante das formas de erosão traduz a combinação entre os fatores internos, como as características pedológicas, litologicas e geomorfológicas, intimamente vinculadas à susceptibilidade à erosão, face aos fatores externos, como o clima e a ação antrópica.

\section{Voçoroca do córrego Tucum: evolução e riscos associados}

A sub-bacia do Córrego Tucum, afluente da Bacia do Ribeirão Araquá, exemplifica de forma consistente a intensificação dos processos erosivos vinculada à expansão dos loteamentos do sítio urbano; arruamentos que acompanham o sentido da inclinação dos terrenos; construção inadequada das estradase a retirada constante de sedimentos efetuada pelos portos de areia, conforme já mencionado anteriormente. A estes aspectos podem ser somados a influência das transformações ocorridas no uso agrícola do solo, o que permitiu a substituição da vegetação natural por outras atividades agro-pecuárias.

Nas cabeceiras do Córrego Tucum situa-se uma voçoroca (fot. 1) que já foi considerada uma das maiores do Estado de São Paulo, chegando a apresentar $60 \mathrm{~m}$ de profundidade e $2 \mathrm{~km}$ de extensão.

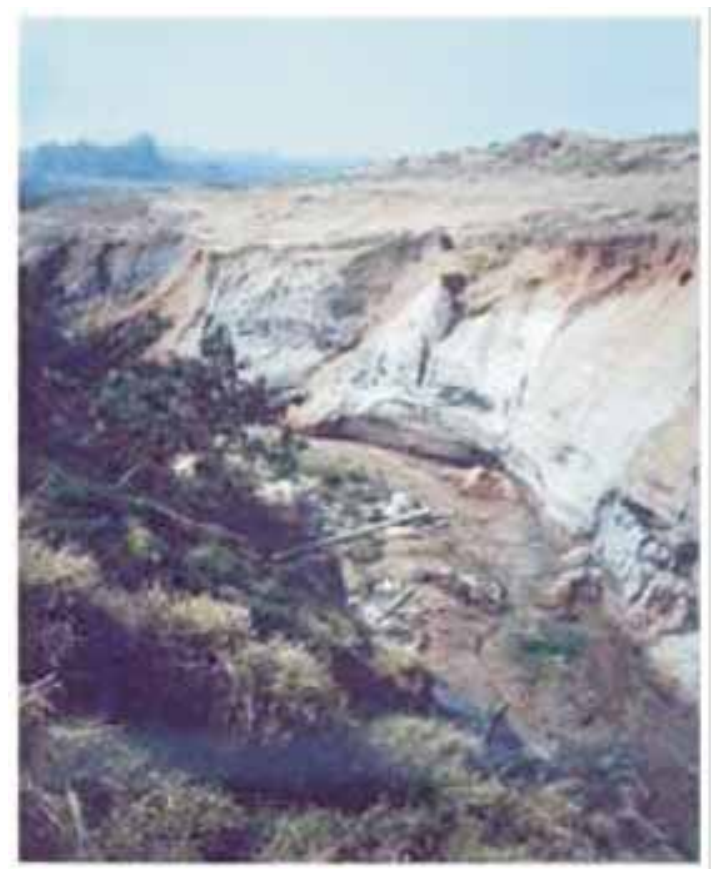

Fot. 1 -Vista parcial da voçoroca do Córrego Tucum.

Anteriormente à obra de contenção, realizada em 1991, a voçoroca foi objeto de estudo de SANCHEZ et al. (1986-1987) que realizaram seu monitoramento no período compreendido entre 1962-78-86, através de fotointerpretação e levantamento topográfico no campo. Segundo essa pesquisa, as características da área eram as seguintes:

Em 1962, o uso da terra se apresentava com pastagens de má qualidade, cerrado e silvicultura. Em porções restritas, apareciam também áreas com cobertura vegetal constituída de matas, capoeiras e matas galerias. Relacionados aos aspectos geomorfológicos, observou-se nas vertentes o escoamento difuso em suas partes superiores, além de sulcos e ravinas nas porções médias, principalmente nas margens do Córrego Tucum. O córrego, mesmo localizado distante da área urbana e da rede viária, apresentava grande quantidade de sedimentos em seu leito, indicando que o processo erosivo já se fazia presente com forte intensidade na área. 
Em 1978, as mudanças observadas no uso da terra, relacionadas à rede viária, constituíram na desativação da Rodovia Geraldo de Barros (SP 191) ou Rodovia São Manuel - Charqueada, atingida pela expansão da voçoroca, tendo sido necessário o traçado de uma nova rodovia. Constatou-se também o avanço dos loteamentos e casas até as cabeceiras do Tucum. Como conseqüência verificou-se o aumento da quantidade de sulcos e ravinas, em ambas as margens do córrego.

Até 1986, verificou-se que, em decorrência dos processos de expansão da voçoroca, houve aumento da área ocupada pela sub-bacia do Córrego Tucunzinho. Também foram verificadas alterações do perfil Iongitudinal, uma vez que sua extensão rumo à montante foi ampliada, bem como seu desnível, devido ao aprofundamento do canal fluvial. A erosão remontante provocou o prolongamento do afloramento do lençol freático do referido córrego em direção às suas cabeceiras. Tais processos contribuíram significativamente para com o acréscimo da área ocupada pela voçoroca.

O alargamento, aprofundamento e a proliferação de sulcos e ravinas possibilitaram a origem de novas voçorocas, com o afloramento do lençol freático em novos locais. Desta forma, o risco de destruição das construções civis existentes (casas e estradas) continuou aumentando.

Com o objetivo de tentar conter o avanço linear e as ramificações das voçorocas do alto curso da bacia do Córrego Tucum, a Prefeitura Municipal de São Pedro decidiu, em 1991, fazer terraplenagem e soterramento dos sulcos e ravinas, utilizando-se de grande quantidade de material arenoso trazida de outros locais. As máquinas soterraram os trechos das voçorocas que apresentavam afloramento do lençol freático, inclusive a nascente do Córrego Tucunzinho, com exceção de seu ramo direito, onde o soterramento foi apenas parcial.

Toda a área submetida à técnica de contenção ficou exposta livremente à ação das chuvas e do escoamento pluvial, aspecto este intensificado pelo manejo intenso realizado pelas máquinas, que constantemente provocavam o revolvimento do solo. Tais fatores propiciaram a reativação dos processos erosivos na área, descritos por CARPI J R (1996), que realizou monitoramento da área entre 1992 e 1996.

Outro problema, já existente em outras épocas e ainda observado constitui-se na ameaça de desabamento de casas do Bairro São Dimas, localizado nas proximidades, devido ao avanço remontante dos sulcos erosivos. Essas casas foram construídas próximas dos taludes das voçorocas e as obras de tentativa de contenção trouxeram a falsa idéia de que se tornariam livres dessa ameaça. Quanto às áreas das nascentes do Córrego Tucunzinho, continuava evidente a constante aceleração dos processos erosivos, com a reativação da antiga voçoroca aí situada.
No decorrer do ano de 1995, confirmavam-se as tendências apresentadas anteriormente relativas à evolução generalizada dos processos erosivos em toda a área. 0 fenômeno que mais despertou interesse nesse período refere-se à destruição total do trecho da rodovia Charqueada - Santa Maria próximo do Córrego Tucum, juntamente com a queda da ponte sobre o referido rio.

Nessa época, ocorreu a pavimentação de diversas ruas pertencentes ao Bairro São Dimas, favorecendo um maior escoamento de água através das vertentes, e o constante assoreamento do leito do Córrego Tucum, provocando o seu alargamento através da erosão lateral.

O acúmulo progressivo de sedimentos no leito e nas margens do Córrego Tucum causou efeitos danosos também à vegetação ciliar situada nessa área, principalmente em direção à jusante até próximo ao local da antiga ponte. Em meados de 1995, foi observado o recobrimento parcial da vegetação, seja rasteira, arbustiva ou arbórea, por parte desses sedimentos arenosos, juntamente com a água retida neles, provocando a morte generalizada das espécies vegetais.

No antigo trecho da Rodovia São Pedro - Charqueada, o avanço de alguns ramos da voçoroca trouxe ameaças para o novo caminho de acesso à cidade de São Pedro. Nas proximidades, em uma área de cabeceira da voçoroca, foi instalado um aterro para lixo, constituindo-se assim outro problema de ordem ambiental, haja vista, dentre outros, o acentuado risco de erosão remontante na mesma.

Sobre a questão dos depósitos de lixo na área, Carrara (2005) explica que durante pelo menos três décadas, desde o início dos anos 70, os resíduos domiciliares dos municípios de São Pedro e Águas de São Pedro, foram depositados no "Lixão Municipal", que se localiza na extremidade leste do perímetro urbano de São Pedro e possui área de aproximadamente 10 hectares. Próximo ao "lixão" existe uma das nascentes do Córrego Tucum, com fragmentos isolados de mata ciliar.

Em decorrência de muita pressão da Promotoria Pública e da sociedade civil, além de autos de inspeção e posteriormente multas aplicadas pela CETESB, o "lixão" que não possuía qualquer estrutura do ponto de vista técnico para barrar o possível processo de contaminação do solo e do lençol freático da região, da região, continuou a existir, inclusive com a presença, nessa época (2002), de várias famílias garimpando os materiais recicláveis nos montes de lixo que os caminhões depositavam diariamente.

No decorrer dos anos de 2003 e 2004, o perímetro da área foi isolado com cercas. Foram também executadas obras de contenção das águas pluviais, através de terraceamento do terreno, plantio de gramíneas e obras de engenharia com vias a permitir o escoamento de águas pluviais, a partir de duas redes com aproximadamente 
500 metros de extensão, em cada ramificação da voçoroca. Tais medidas foram necessárias, haja vista que as tubulações instaladas anteriormente foram destruídas pela dinâmica erosiva (fot. 2).

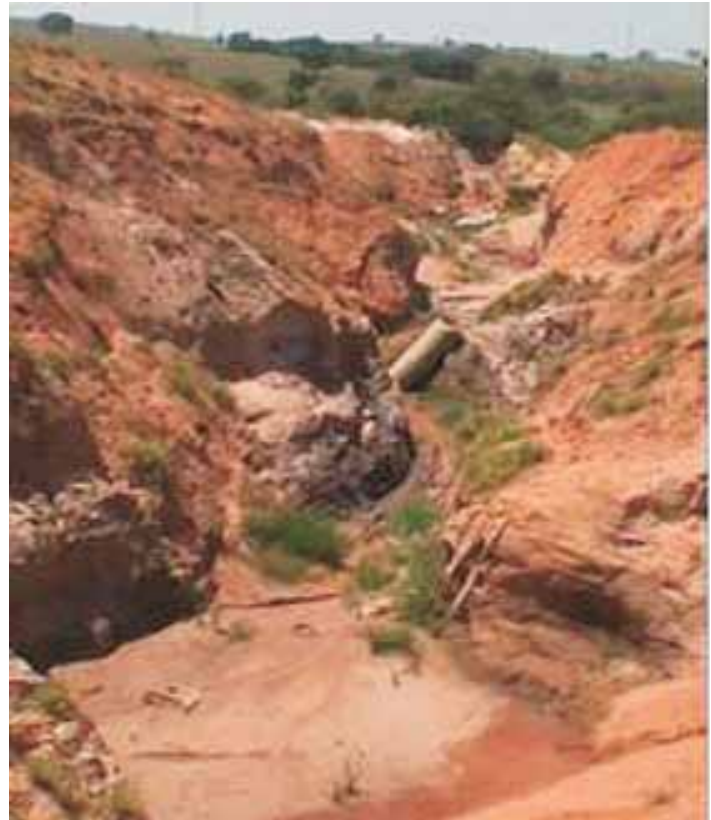

Fot. 2 - Vista parcial da voçoroca com tubulações destruídas.

Além disso, foi efetuado neste mesmo período o desvio do esgoto, que antes era lançado na voçoroca, em conjunto com início de obras para a criação de uma rede de tratamento para o mesmo (fot. 3).

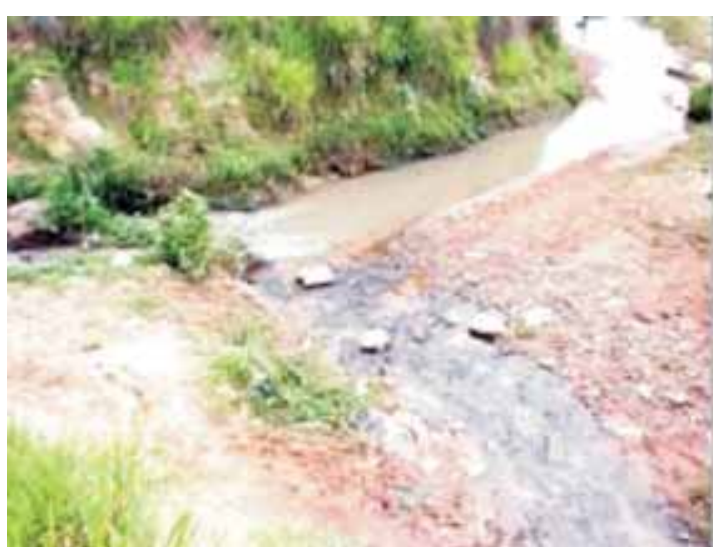

Fot. 3 - Lançamento de Esgoto in natura no Córrego Tucunzinho.

Fonte: CARRara (2005).

Mesmo com tais intervenções, Carrara (2005) notou que os líquidos provenientes da decomposição da grande quantidade de materiais ali depositados continuavam percolando o solo, colocando em risco de contaminação a qualidade da água do Córrego Tucunzinho, que é formador do Córrego Tucum e Araquá, além do lençol freático de toda a região.
Recentemente surgiu outro ponto (fot. 4) de destinação de resíduos na cidade. Trata-se de um local localizado no bairro São Dimas, próximo à área do antigo "lixão" (fig. 2), que recebe descarte clandestino de resíduos domésticos, carcaças de animais, materiais inertes e restos de podas de árvores.

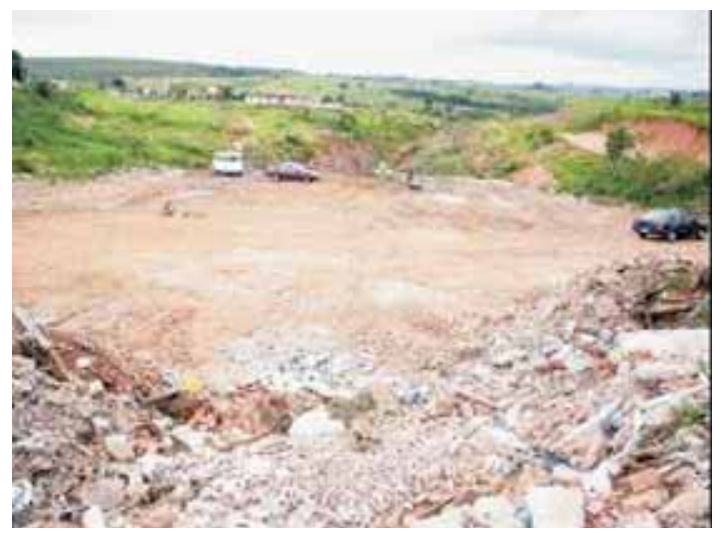

Fot. 4: Área clandestina de deposição de lixo. Fonte: Carrara (2005).

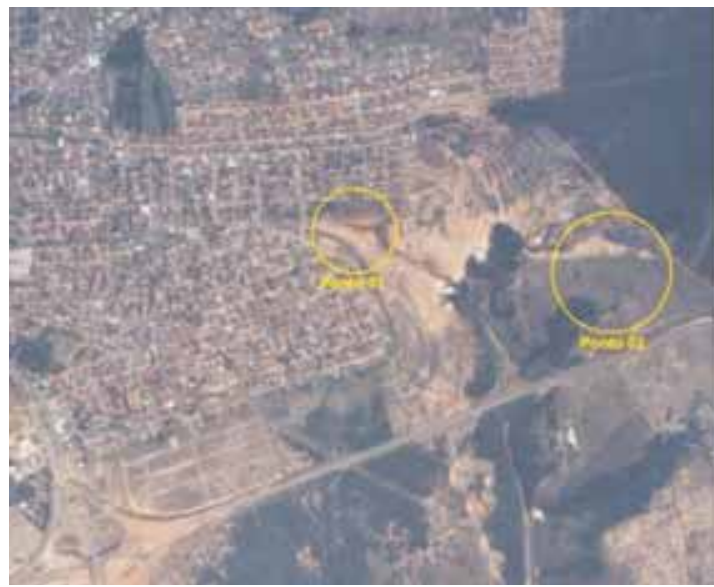

Fig. 2 - Área clandestina de destinação de resíduos, sendo ponto 01: área clandestina atual; ponto 02: área do antigo Lixão Municipal, desativada em 2003.

A área é particular e, por estar localizada na cabeceira de uma das ramificações da voçoroca, apresenta assim grande fragilidade. Constantemente o proprietário e a Prefeitura fazem a manutenção do terraceamento do terreno. Apesar da deposição clandestina de lixo, os moradores transitam pela área, através de "atalhos", que são usados por pedestres e pessoas com veículos, para terem acesso a bairros vizinhos. 0 trânsito intenso na área poderia provocar a desestabilização dos taludes, podendo formar caminhos preferenciais para aumentar a energia das águas da chuva e agravar o já grave processo erosivo da área.

Houve denúncia na Promotoria Pública, que acionou a Prefeitura Municipal para dar solução ao problema, pois, além da possibilidade de contaminação do solo e da 
água, o local fica muito próximo de imóveis residenciais, que são afetados pela presença de animais e insetos, atraídos por lixo e materiais orgânicos em decomposição, servindo de vetores para inúmeras doenças e tornando-se um risco à saúde pública. A Secretaria Municipal de Meio Ambiente realizou al gumas intervenções no local, como 0 início do isolamento da área e a primeira análise da água da nascente, coletada em 08/ 06/ 2005 num único ponto, cujos resultados apesar de não indicarem contaminação por metais pesados, verificaram a presença de materiais graxos.

Em 2008 foram realizados trabalhos de campo na área de estudo, os quais possibilitaram verificar mais recentemente a dinâmica dos processos erosivos, bem como a do uso e ocupação das terras. Verificou-se a construção em áreas terraplanadas da voçoroca, ou seja, em área de risco, de estação de tratamento de esgoto, cemitério, e escola (fot. 5).
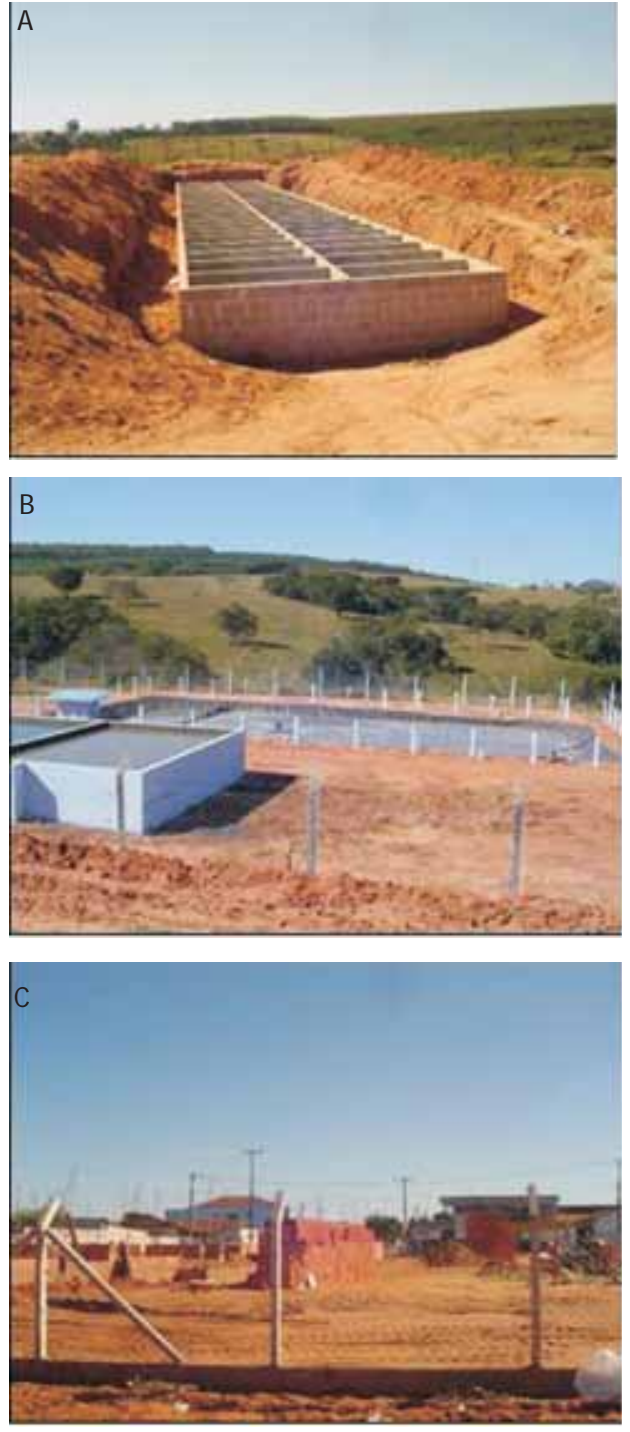

Fot. 5 - Obras civis em áreas de risco, sendo A: cemitério; B: estação de tratamento de esgoto; C: escola.
Tais obras civis foram autorizadas e construídas sobre os terraços implantados no interior da voçoroca. 0 material constituinte de tais terraços, como citado anteriormente, possui grande fragilidade, haja vista sua pouca coesão, pois consiste de material arenoso, transportado e constantemente revolvido por máquinas desde o início dos anos 90 (fot. 6). Além disso, verificouse a presença de abatimentos (subsidência do terreno) em grande parte de tais terraços, a exemplo da própria área do referido loteamento.

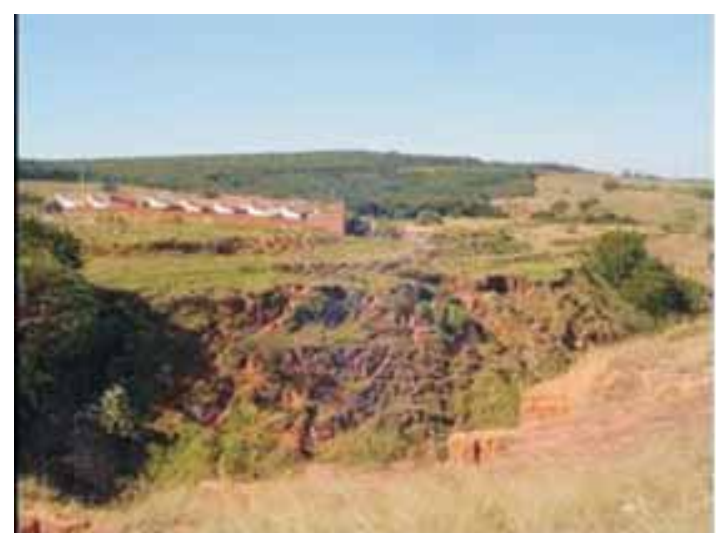

Fot. 6 - Loteamento para população de baixa renda, construído em área de risco (terraços arenosos de pouca coesão).

Dado o histórico de destruição dos terraços implantados inadequadamente nos últimos 18 anos, e o constante surgimento de sulcos erosivos, que podem evoluir rapidamente para novas ravinas (fot. 7) é possível afirmar que todas essas obras civis podem futuramente ficarem comprometidas pela dinâmica dos processos geomorfológicos existentes.
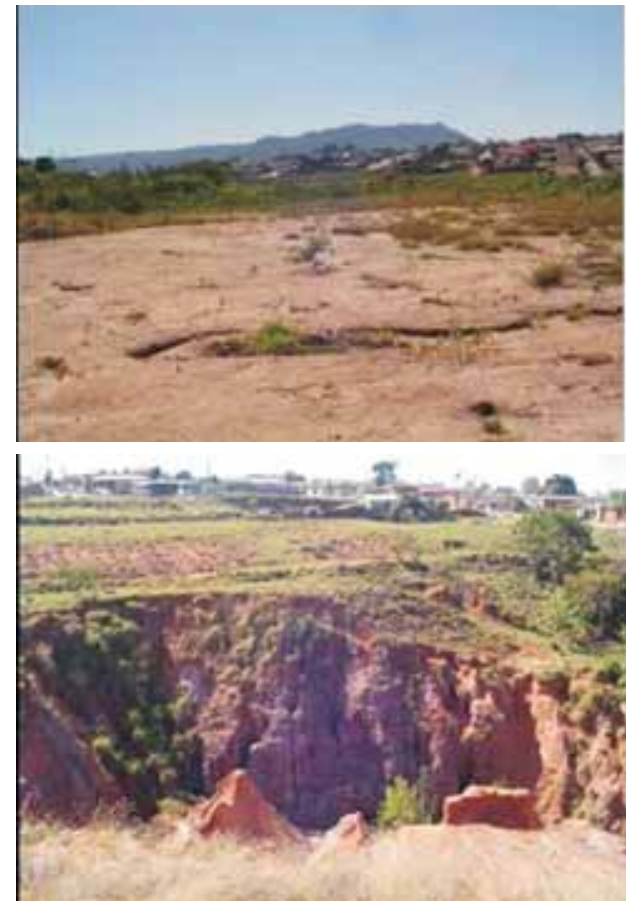

Fot. 7 - Formação de sulcos erosivos e ravinas nas proximidades da voçoroca. 
A implantação de tais obras poderão também modificar as características do escoamento superficial da água criando novas superfícies impermeabilizadas e novos caminhos preferenciais para a água de origem pluvial. Além disso, a estação de tratamento de esgoto e o cemitério representam riscos de contaminação do lençol freático, que localmente alimenta o Córrego Tucum.

\section{Conclusão}

0 presente trabalho demonstra que os processos erosivos presentes em São Pedro, apesar de possuírem gênese natural, têm sido intensificados por ações inadequadamente implementadas pelo poder público municipal. Tal fato se processa fundamentalmente pelo distanciamento deste em relação ao conhecimento científico sistematicamente produzido pelo meio acadêmico ao longo das últimas décadas.

Espera-se que, com o início das atividades relacionadas ao Plano Diretor Municipal, tal conhecimento seja considerado, principalmente no que concerne às fragilidades ambientais inerentes à área de estudo, para que, deste modo, os efeitos danosos da erosão possam ser reduzidos e haja maior equilíbrio na relação homem/ natureza.

\section{Referências Bibliográficas}

CARPI J UNIOR, Salvador. Técnicas Cartográficas Aplicadas à Dinâmica Ambiental da Bacia do Ribeirão Araquá-SP. Rio Claro: IGCE-UNESP-Rio Claro, 1996. (Dissertação de Mestrado).

Carrara, S.L. Subsídios para o Planejamento Ambiental do Município de São Pedro/SP. São Pedro, SP,
2005. (Monografia de Especialização em Gestão Ambiental, Faculdade de Engenharia Mecânica, Universidade Estadual de Campinas).

FACINCANI, E. M. Influência da estrutura e tectônica no desenvolvimento das boçorocas da Região de São Pedro(SP): proposta de reabilitação e aspectos jurídicos-institucionais correlatos. Rio Claro: UNESP, 124p. Dissertação (Mestrado em Geociências e Meio Ambiente). IGCE, UNESP.

INSTITUTO DE PESQUISAS TECNOLÓGICAS DO ESTADO DE SÃO PAULO. Mapa Geológico do Estado de São Paulo. São Paulo: 1981. Esc. 1:500.000. 2v.

Oliveira, J. B., Jacomine, P. K. T., Camargo, M. N. Classes gerais de solos do Brasil: guia auxiliar para 0 seu reconhecimento. J aboticabal: FUNDUNESP, 1992. $201 \mathrm{p}$.

Perez $F^{0}$, A ; Nogueira, F. P; Sanchez, M. C. e Tavares, A. C. Erosão acelerada em areias quartzosas no Município de São Pedro. In: REUNIÃO ANUAL DA SOCIEDADE BRASILEIRA PARA O PROGRESSO DA CIÊNCIA, 38a ${ }^{a}$, Curitiba (PR). Anais da reunião anual da SBPC. Curitiba: SBPC, 1986.

Sanchez, M. C.; Mendes, I. A.; Freitas, M. I. C.; Lorenzon FILho, A. V. Monitoramento de forma de erosão acelerada no Córrego Tucunzinho no Município de São Pedro (SP - BR). In: Boletim de Geografia Teorética. Rio Claro, vol. 16 (31 - 34), p. 276 284, 1986 - 1987.

Outras Fontes:

Sítio consultado: http:// www.citybrazil.com.br/sp/ regioes/piracicaba/ 